\title{
SOLITARY FIBROUS TUMOUR OF KIDNEY: A RARE CASE REPORT
}

\author{
A. Sinha ${ }^{1}$, Navin Shankar K. R², R. N. Singh ${ }^{3}$, N. K. Ray ${ }^{4}$
}

\section{HOW TO CITE THIS ARTICLE:}

A. Sinha, Navin Shankar K. R, R. N. Singh, N. K. Ray. "Solitary Fibrous Tumour of Kidney: A Rare Case Report". Journal of Evolution of Medical and Dental Sciences 2015; Vol. 4, Issue 52, June 29; Page: 9129-9133,

DOI: $10.14260 /$ jemds/2015/1325

ABSTRACT: A solitary fibrous tumor (SFT) is an unusual spindle cell neoplasm that usually occurs in the pleura but has been described in diverse extrapleural sites. Herein we report a case of solitary fibrous tumor of kidney in a 60 year old female which was clinically suspected as renal cell carcinoma but proved to be solitary fibrous tumor histopathologically and was confirmed by immunohistochemistry. We report this case because of its rarity and to discuss the important differentials that has to be considered in a case of renal mass.

KEYWORDS: Solitary fibrous tumor, Kidney, Spindle cell tumor.

INTRODUCTION: Solitary fibrous tumors (SFTs) are distinctive mesenchymal tumors most commonly described as pleural-based lesions; however they can develop at any extrapleural anatomic site.[1] Since their initial description in the pleura by Klemperer and Rabin in 1931[1] SFTs have been reported to arise at nearly every site in the body.[2] In general, they are slow-growing tumors with a favorable prognosis, although there have been some malignant cases.[3] SFTs arising in the kidney were first described in 1996 by Gelbet al.[4]; however, few cases, particularly those involving malignancy, have been reported in the worldwide literature to date.[5] A high degree of suspicion is necessary since clinical presentation of the disease may mimic renal cell carcinoma.

CASE REPORT: A 60 years old female presented with complaints of abdominal mass and abdominal pain since 2 years. History of loss of appetite and loss of weight was present. No history of vomiting, constipation, diarrhoea, hematuria was present. Patient was undernourished with normal pulse rate and blood pressure. On examination of abdomen, there was a mass of size 20x18 cm involving the epigastric, left hypochondrium, left lumbar region. The surface was nodular and firm to hard in consistency. Mass freely moved with respiration. A band of resonance was noted over the mass on percussion. Ultrasound abdomen and CT scan showed renal mass of size 20x19 cm arising from the upper pole of left kidney. In view of clinical and CT findings laparotomy was performed through midline incision. Large 20x19 cm well circumscribed mass arising from left kidney was found. Left nephrectomy was perfomed and the specimen was sent for histopathological examination.

Microscopy showed a well circumscribed encapsulated tumor mass with hyper and hypocellular areas. The hypercellular areas composed of benign looking spindle cells arranged in storiform pattern. The hypocellular areas show presence of keloid like collagen along with blood vessels showing hemangiopericytomatous appearance. No areas of hemorrhage and necrosis noted. Mitosis was 1/10 high power field. Rest of the kidney appears to be histomorphologically normal. With these findings a diagnosis of solitary fibrous tumor of kidney was made and immunohistochemistry for CD34, and CD99 were done which came out to be positive and S-100, smooth muscle markers, and cytokeratin were negative thus confirming the diagnosis of solitary fibrous tumor of kidney. 


\section{CASE REPORT}

DISCUSSION: The solitary fibrous tumor (SFT) is a rare but well-established neoplasm. Indeed, in 1942, Stout and Murray[6] introduced the concept that hemangiopericytoma originated from the pericytes of blood vessels. In 1994, Fletcher[7] proposed that hemangiopericytomas are heterogeneous in nature and may consist of SFTs and other distinctive soft tissue tumors, although the concept of hemangiopericytoma had been widely accepted. The new edition of the World Health Organization classification describes "hemangiopericytoma" as consisting of SFT and related conditions, including giant cell angiofibroma and lipomatous hemangiopericytoma.

Extrapleural solitary fibrous tumors have occurred in the upper respiratory tract, lung, nasal cavity, paranasal sinuses, orbits, mediastinum, major salivary glands, breast, meninges, liver, and urogenital organs. Of the renal SFTs reported in the literature during the past 10 years, more than $50 \%$ have occurred in patients older than 40 years (from 33 to 76 years, with an average age of 52 years. The origin of most cases of SFT of the kidney is difficult to determine. Some reported cases of solitary fibrous tumor of the kidney were reported to have originated from the renal capsule. The male-to-female ratio appears to be almost equal (1:1.5).

In our case study, the tumor exhibited a unique growth pattern as a primary tumor of the kidney. The tumor involved not only the renal cortex but also the extrarenal soft tissue, suggesting the possibility of a renal surface origin of the tumor. Interestingly, one case has been reported which showed an intra renal growth pattern without connection to the renal capsule or renal pelvis.[8] Further research is necessary to clarify the pathogenesis of these rare tumors.

Grossly, the renal SFTs reported in the literature ranged from 2 to $25 \mathrm{~cm}$ (mean, $8.75 \mathrm{~cm}$ ). Most of the lesions were described as well-circumscribed or pseudoencapsulated, lobulated, rubbery or firm masses with a homogeneous, gray or tan-white, whorled cut surface.[2]

In all the reported cases of SFT of the kidney, final diagnosis was made by means of histopathological examination. All tumors were characterized by spindle cell proliferation showing a patternless architecture with a combination of alternating hypocellular and hypercellular areas separated from each other by thick bands of hyalinized, somewhat keloidal collagen and branching hemangiopericytoma-like vessels.[2]

CD34 immunoreactivity has been reportedly shown to be strongly and diffusely expressed in many cases of SFT, and although it is not specific for SFT, strong CD34 reactivity is currently regarded as characteristic and an indispensable finding in the diagnosis of SFT. Seventy percent of SFTs express CD99 and Bcl-2; only $20 \%$ to $35 \%$ are variably positive for epithelial membrane antigen and smooth muscle actin. Focal and limited reactivity of S-100 protein, cytokeratins, and/or desmin has also occasionally been reported.

Mesenchymal tumors that should be differentiated from SFT include sarcomatoid renal cell carcinoma, fibroma, fibrosarcoma, leiomyoma, leiomyosarcoma, schwannoma, malignant peripheral nerve sheath tumor, hemangioma, angiosarcoma, synovial sarcoma, and gastrointestinal stromal tumor because some of these tumors typically show hemangiopericytomatous patterns. Diffuse positive expression of CD34, Bcl-2, and CD99 and negative expression of cytokeratin, $\alpha-S M A, S-100$, CD31, and c-kit are useful for their differential diagnosis.[9]

Although most cases are benign, the behavior of SFTs is unpredictable. It is estimated that $10 \%$ to $15 \%$ of intrathoracic SFTs and up to $10 \%$ of extrathoracic SFTs will recur and/ or metastasize.[10] The histopathologic features related to clinical malignancy include increased cellularity, pleomorphism, increased mitotic activity ( $>4$ mitoses/10 high-power fields), necrosis, 
hemorrhage, and atypical location (parietal pleura, pulmonary parenchyma). However, there is far less information regarding the behavior of extrathoracic SFTs.[11]

CONCLUSION: Hence it is important to consider solitary fibrous tumor in the differential diagnosis in all cases of renal cell mass and has to be differentiated from other spindle cell tumor of kidney. It is also important to know whether it is malignant as malignant solitary fibrous tumor though rare do occur and cases have been reported in the literature.

\section{REFERENCES:}

1. Klemperer P, Rabin CB. Primary neoplasm of the pleura: a report of five cases. Arch Pathol.1931; 11: 385-412.

2. Gelb AB, Simmons ML, Weidner N. Solitary fibrous tumor involving the renal capsule. Am J SurgPathol. 1996; 20: 1288-1295.

3. Fain JS, Eble J, Nascimento AG, et al. Solitary fibrous tumor of the kidney: report of three cases. J UrolPathol. 1996; 4: 227-238.

4. Hasegawa T, Matsuno Y, Shimoda T, et al. Extrathoracic solitary fibrous tumors: their histological variability and potentially aggressive behavior. Hum Pathol. 1999;30:1464-14735.

5. Yazaki T, Satoh S, Iizumi T, et al. Solitary fibrous tumor of renal pelvis. Int J Urol. 2001;8:504508

6. Stout AP, Murray MR. Hemangiopericytoma: a vascular tumor featuring Zimmerman's pericytes. Ann Surg. 1942; 116: 26-33.

7. Fletcher CDM. Haemangiopericytoma. A dying breed? Reappraisal of an entity and its variants: a hypothesis. CurrDiagPathol. 1994; 1: 19-23.

8. Wang J, Arber DA, Frankel K, et al. Large solitary fibrous tumor of the kidney: report of two cases and review of the literature. Am J SurgPathol. 2001; 25: 1194-11998.

9. Magro G, Cavallaro V, Torrisi A, et al. Intrarenal solitary fibrous tumor of the kidney report of a case with emphasis on the differential diagnosis in the wide spectrum of monomorphous spindle cell tumors of the kidney. Pathol Res Pract. 2002; 198: 37-43.

10. Weiss SW, Goldblum JR: Soft tissue tumors of intermediate malignancy of uncertain type. In Soft Tissue Tumor. 5 edition. Edited by: Weiss SW, Goldblum JR. Philadephia: Mosby Elsevier; 2008:1093-1160.

11. Guillou L, Fletcher JA, Fletcher CDM, et al. Extrapleural solitary fibrous tumour and haemangiopericytoma: World Health Organization classification of tumours. In: Fletcher CDM, Unni KK, Mertens F, et al., editors. Pathology and Genetics of Tumours of Soft Tissue and Bone. Lyon, France: IARC Press; 2002. pp. 86-90. 


\section{CASE REPORT}
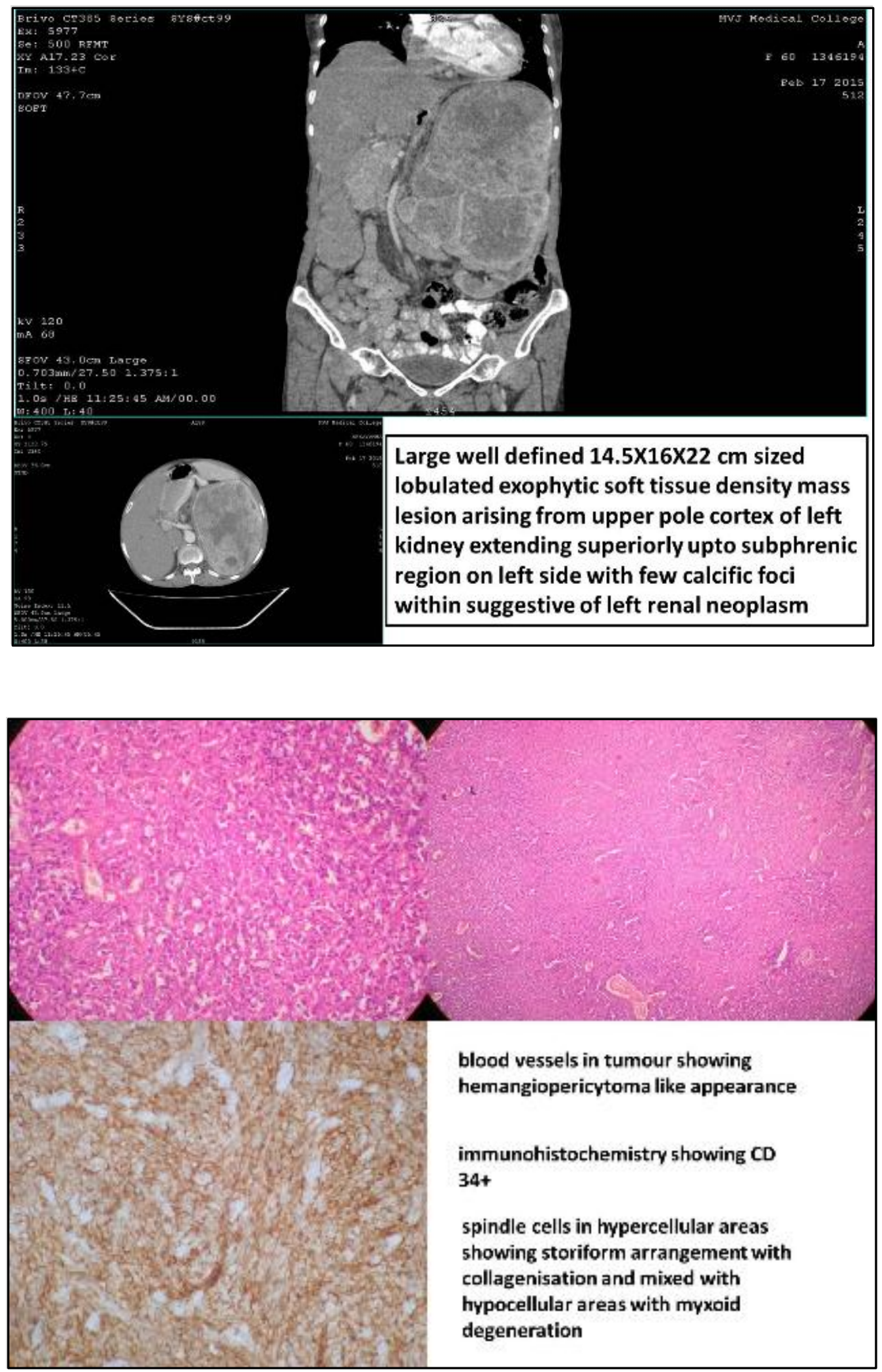


\section{CASE REPORT}

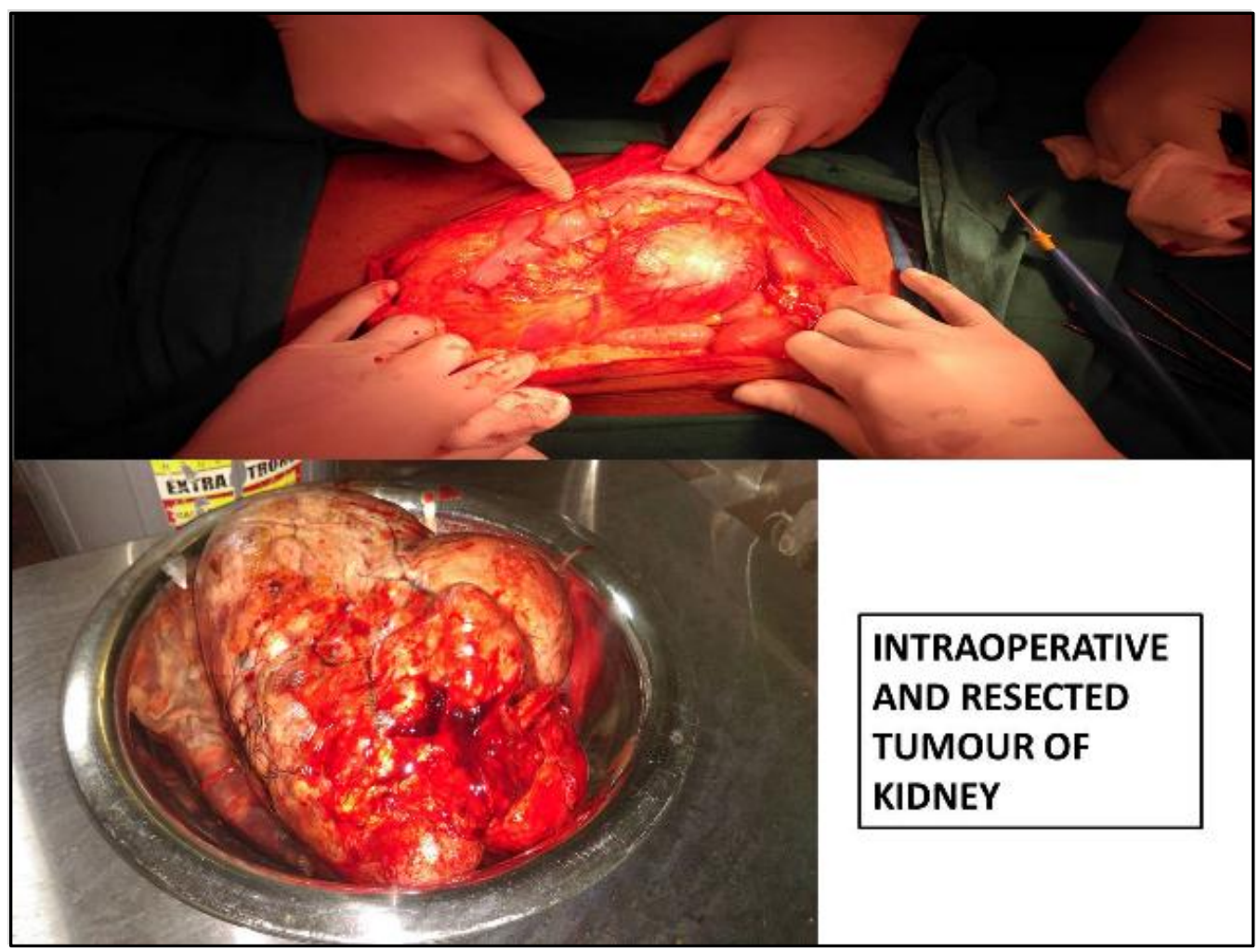

\section{AUTHORS:}

1. A. Sinha

2. Navin Shankar K. R.

3. R. N. Singh

4. N. K. Ray

\section{PARTICULARS OF CONTRIBUTORS:}

1. Assistant Professor, Department of General Surgery, MVJMC \& RH, Bangalore.

2. Post Graduate, Department of General Surgery, MVJMC \& RH, Bangalore.

3. Assistant Professor, Department of General Surgery, MVJMC \& RH, Bangalore.

FINANCIAL OR OTHER COMPETING INTERESTS: None
4. Professor \& HOD, Department of General Surgery, MVJMC \& RH, Bangalore.

\section{NAME ADDRESS EMAIL ID OF THE} CORRESPONDING AUTHOR:

Dr. A. Sinha,

Flat No. D-0, Shilpitha Crystal Apartments, $6^{\text {th }}$ Cross, Kaggadaspura,

Bangalore-560093.

E-mail: arunabha_singa@yahoo.com

Date of Submission: 06/06/2015.

Date of Peer Review: 07/06/2015.

Date of Acceptance: 22/06/2015.

Date of Publishing: 29/06/2015. 